\title{
A conversation with Bert Vogelstein and Ken Kinzler
}

In the United States alone, every year, nearly two million people are diagnosed with cancer, and much of what we know about the genetics of cancer comes from the work of two legendary scientists, Bert Vogelstein and Ken Kinzler (Figure 1) of the Ludwig Center at the Johns Hopkins Sidney Kimmel Comprehensive Cancer Center. To hear their turn as stand-up comedians, see the full interview on the JCI website at http://jci.org/videos/cgms.

JCI: What were you like as boys?

Kinzler: I liked to take things apart and sometimes put them back together, but unfortunately, mostly take things apart. I very much liked reading about science and science fiction. I grew up in Northeast Philadelphia in one of the row houses very close to a jail. I worked, as a teenager, in a deli and we sold a lot of lottery tickets to people who worked at the jail.

My father was an engineer, so he taught me about math, science, and engineering and, specifically, providing solutions to problems. I had an interest in cancer, and to this day, I don't know why I thought cancer was an interesting problem, but that actually led me into the field of toxicology because it gave me exposure to cancer biology at the undergraduate level. My parents were older than the typical parents: my father was 50 when I was born, but it's not like they were affected by cancer.

$J C I$ : What led you to graduate school?

Kinzler: As an undergraduate, I was pretty clueless. Another attractive thing about toxicology was that you could get a job doing science, which is what I intended to do as soon as I graduated. I did an internship in industry, and when I came back my senior year, I talked to the program director and he said, "You know, you can go to graduate school." And I said, "What's graduate school?" "You can get a PhD." I said, "What's a PhD?" And he said, "And they'll pay you to do that." I said, "Oh, okay." I managed to take the GREs, but I was late to the game and managed to apply only to a few schools whose dead-

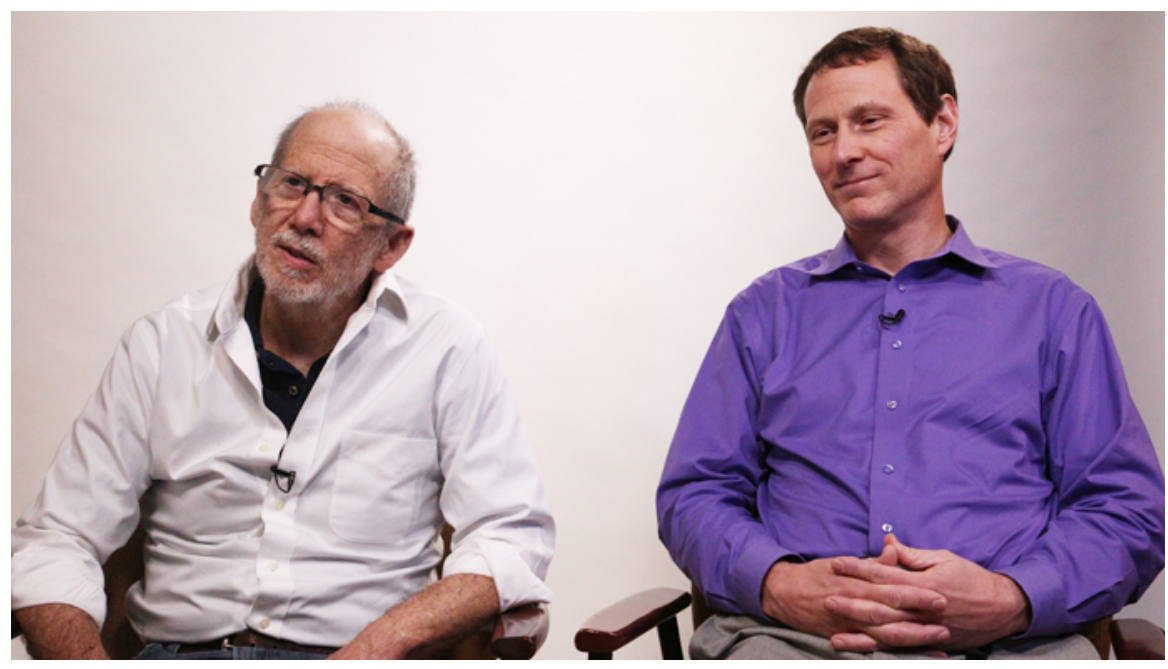

Figure 1. Bert Vogelstein and Ken Kinzler on February 24, 2016, in Baltimore, Maryland, USA. Photo credit: Thomas Wach.

lines hadn't yet passed. Fortunately, Hopkins gave me a chance.

Vogelstein: I grew up in Baltimore. I liked it here and never saw any reason to leave, so I'm still here. I didn't come from a scientific family. My father was an attorney, and my grandfather was a rabbi. I hated school. After a while, I stopped going and started going to the library and reading instead, and I got away with that for quite a bit of time, until I was asked to leave my private school and went back to public school. I had three brothers and a sister fairly close in age. Reasonably competitive. My father instilled a sense of competition into us. And we're still a very close family; everyone still lives in Baltimore.

JCI: When along this path did you get introduced to science and math?

Vogelstein: Well, even when I was in grade school, the subjects I did best in were math and science. Some of the other subjects were a struggle in the sense that I wasn't very interested, but I loved the logic that was involved in science and particularly in mathematics. Somewhere in my teenage years, I saw a pamphlet that Hopkins had issued called, "The Making of a Physician," and it made an impact on me. I anticipated always doing some sort of research, and that really crystallized when I was a resident in pediatrics.

I originally thought of going into math, but what convinced me to go to medical school was two things. First, it wasn't clear to me that I was smart enough to go into math. I saw how smart and insightful my professors were, and it wasn't clear to me that I had that kind of insight. Second, though I hated biology in college, as it was incredibly boring, it offered a route to help people that might have been quicker than what I could have accomplished in mathematics. So for those two reasons, I decided to apply to medical school, and of course, I wanted to come to Hopkins, and I was fortunate enough to be accepted.

JCI: There's a famous story that during your internship, you encountered a family with a four-year-old daughter who you diagnosed with leukemia. Why did that particular girl drive you to choose to focus your research career on cancer? Why wasn't it an autistic child or someone with a neurodegenerative disease?

Vogelstein: I think many decisions in life are experiential. It's not something you read but something that makes a deep impact on you. The little girl that presented with leukemia - her father was a mathematician who taught at a local college and was essentially my age. I immediately identified with him. While we were going 
through the process of diagnosis, he asked me "Why did this happen to my precious little girl?" And right at that point, I realized he was a professional, he wanted a serious answer, and I had no answer. And no one else in the world did either. Not only that, what he really wanted to know was, "Did I do anything? Or did my wife and I do anything that caused my beautiful little girl to have this horrible condition?"

I told him the standard answer. "You had nothing to do with it." But in reality, I didn't know. Maybe he spent too much time with his daughter in the garage painting. Paint has benzene; benzene is a known carcinogen. I couldn't really answer him definitively. Ten years from then, if another beautiful little girl gets leukemia, would we be in the same place? It was an epiphany. It seemed to me that this would be a valuable thing to spend one's life on. Trying to find out what's going on and hoping that that information could eventually allow someone to look right in the eye of a parent and say, "This is what caused your little girl's disease." And in the distant future, "We know what caused it and we know how to get rid of it."

JCI: Ken, as you were doing your $\mathrm{PhD}$, did you know that you wanted to work with Bert?

Kinzler: The short answer is no. I wanted to do cancer research, and I had some idea that I wanted to do some genetics research. I picked a program that had an anticancer drug development program, and I was going to come to Hopkins, get my $\mathrm{PhD}$, and then go into industry. I had no idea about professors or academics; I was pretty naive at the time, but fortunately, the pharmacology program gave me a chance, and then I did my first rotation with Bert.

It's actually quite interesting. I was sitting in the Director of the Pharm Program's office, and you called and said you needed a student.

Vogelstein: I'm not sure I ever knew that. Did I?

Kinzler: Yep, I was in Mette Strand's office and you literally called at that time; you were in the cancer center, you were doing some neat stuff, and I didn't take long to realize that you were obviously a genius and a great person to work with.

JCI: This is 1983 and you've never left. Why?
Vogelstein: I wouldn't let him.

Kinzler: I had to do a rotation in a different laboratory, and then I came back. We were always doing new things. We could argue and exchange thoughts, and it was just always a learning environment, even to this day. If we both approached problems with the same exact approach or the same thoughts and if we never disagreed, there would be no advantage for us to work together. We like nothing more than to argue.

JCI: What is it that Ken brings to the partnership that you didn't have on your own?

Vogelstein: I immediately recognized Ken's talents, as soon as he came to lab and did his first experiment. I used to play and teach a lot of tennis. A good tennis teacher can recognize someone who has extraordinary talent within five minutes. Very few people have it. It's hard to describe, but you know when you see it. I knew immediately Ken was brilliant. Right then, I thought, "He's probably smarter than me." Now, after working with him for 30 years, I know that's true.

Kinzler: That's what I say about him too.

Vogelstein: He's intuitive. Maybe it's my background, but I'm more bookish. When we're considering a new project or considering ways to do something, my approach is to read all the literature for the last 50 years and try to integrate what's known and what's not known and come to some sort of decision about what's optimal to do. Ken just intuits it. He's unfortunately usually right, and I hate to say that on camera, but it's the truth. Those two things intuition plus searches of the literature bring us together.

Kinzler: I think Bert's being a bit modest. When he says literature, he is the literature. He is like Google on legs. I mean, it's just amazing, and he couples that with incredibly rigorous logical and thought processes. That logic is really good for our trainees and good for thinking things through and making sure that we understand a problem in its entirety.

Vogelstein: Could you interview us every day? Because this is not what he usually says.

JCI: It seems like you guys have a yin and a yang thing here, which is part of the reason why you've been so successful over the last 30 years. Your scientific discoveries are pretty legendary. You were the first to discover that P53 was a tumor suppressor. You found that mutations in APC underlie most colorectal cancers. SAGE, digital PCR that presaged liquid biopsies, among many, many others. You've knocked down an amazing series of dominoes. How is it that you have managed this body of research?

Vogelstein: Our end goal is not really publishing papers and making discoveries that turn out to be important. Our end goal is emptying the cancer center across the street in the hospital. To us, the papers are just way stations to the end. We haven't reached what we set out to do. Far from it.

We're continually trying to do new things that get us closer to that goal. We don't do evolutionary research; we try for revolutionary research that opens new fields. I often speak to incoming graduate students who've applied to one of the Hopkins programs, and one of the things I always tell them is, "You're in graduate school because you want to set the world on fire. If you don't want to set the world on fire, then go do something more mundane." As a scientist you have the opportunity to go where no one has ever gone before.

JCI: I've heard you say before, "You should think like a science fiction writer."

Vogelstein: The reason for that is if you ask scientists to predict the future, they are horrible at it because they're so tied to data and reality. If you ask science fiction writers to predict the future, they do it, while thinking of things that aren't possible now, but they're not limited by what we can do now. Ken and I just both feel so incredibly lucky that we're able to do this and that we call this work. I mean this is hardly work.

Kinzler: Talk about a wonderful job. We sometimes take for granted that we get to work with incredibly intelligent and competent people. The trainees that we get to work with are really brilliant. With them, we try to rethink and ask how we can have a major impact. The advice Bert gave me and other trainees when we were young is, "You can never have enough credit or money, so don't pursue those as goals."

One of the things that you originally asked about why we've had one discovery after another - it's partly our approach. But often success can interfere with future 
success. You get invitations to go to meetings; you get invitations to be department chairmen. They're all good things, but they tend to remove you from the laboratory, and it makes it harder to participate in future discoveries. Bert has always set the example and the focus of being there in the laboratory. He's hardly ever not there. I don't think he's gone to more than half a dozen meetings in 30 years, and that has allowed us to focus on the science.

JCI: Can you recall your very first experiment?

Kinzler: It depends on what you classify as an experiment. I tried to pry out an electrical receptacle plug from the wall with a knife and shocked myself. And I used to play with model trains and some of it was 120 volts, and I shocked myself many a time on that. So as a preteen, I used to just electrocute myself a lot. But when I was an undergrad, I had a work-study program that had allowed me to tinker in the physics lab with the physics professor and I wanted to build an NMR. It was cool to be able to cobble things together.

Vogelstein: Before, you asked about the differences between Ken and me that's one of them. He can build instruments. I have no idea what to do when instruments break down other than take them in to Ken's office.

He's really incredible with that kind of thing. We do a lot of genomic sequencing, and sometimes, people ask us if we have a large bioinformatics department in our lab, and I say, "Yeah, incredibly large," and point to him because he's it. He develops all our computer programs, all the bioinformatics single-handedly, and it's pretty impressive, along with his ability to fix any instrument.
JCI: Let's say you could not have been a scientist. What else do you think you could have dedicated yourself to?

Vogelstein: The only alternative career I ever really thought of was a garbage collector, and the reason I'd like that is because you get up early, and you finish collecting the garbage, and then you come back and can spend the rest of the day with your family. That's the only other alternative other than medicine, practicing some sort of specialty in pediatrics, I've ever really considered.

Kinzler: Engineering might be too close to science. But I probably would've done something like electrical engineering or programming. I like building and making new things. I do some carpentry on the side too.

Ushma S. Neill 